\title{
IMPACTOS DA GERAÇÃO E ABSORÇÃO DE CONHECIMENTO NA PRODUTIVIDADE DA FIRMA*
}

\author{
Alexandre Messa Silva
}

\begin{abstract}
RESUMO Este trabalho procura identificar as características do processo de inovação da indústria brasileira, particularmente no que diz respeito às alternativas referentes tanto à absorção do conhecimento gerado externamente - por meio de aquisições de máquinas e equipamentos —, quanto à geração de conhecimento internamente à firma - via dispêndios em pesquisa e desenvolvimento. Nesse sentido, identificaram-se os determinantes da decisão de se investir em cada uma dessas alternativas, do nível desses investimentos, do impacto destes na inovação e desta no desempenho da firma. Entre outras evidências, verificou-se uma maior produtividade marginal por parte dos dispêndios em $\mathrm{P} \& \mathrm{D}$ - em relação a aquisições de M\&E — no processo de inovação da indústria brasileira.
\end{abstract}

Palavras-chave: inovação; P\&D; M\&E; CDM; produtividade

Código JEL: L25; O33; O31

\section{IMPACTS OF KNOWLEDGE PRODUCTION AND ABSORPTION ON THE PRODUCTIVITY OF FIRMS}

ABSTRACT This paper intends to characterize the innovation process in Brazilian industry, especially in what is related to the alternatives of external knowledge absorption - through machines and equipment acquisitions — and internally knowledge generation — via research and development spending. By this way, it was identified the determinants of the decisions about each of the alternatives, the level of these investments, the importance of those to innovate, besides the impact

* Artigo recebido em 19 de setembro de 2007 e aprovado em 15 de setembro de 2009.

** Técnico de Planejamento e Pesquisa do Instituto de Pesquisa Econômica Aplicada (Ipea), e-mail: alexandre.silva@ipea.gov.br 
of the innovation on the firm performance. Among other evidences, it was verified a larger R\&D marginal productivity — in relation to the M\&E acquisitions - in the Brazilian industry innovation process.

Key words: innovation; R\&D; M\&E; CDM; productivity 


\section{INTRODUÇÃO}

Apesar de ter surgido uma ampla literatura econômica acerca das consequências da abertura comercial e financeira vivida pela economia brasileira ao longo da década de 1990, ainda se carece do devido entendimento desse cenário concorrencial surgido deste então. Realmente, se, de um lado, as empresas brasileiras ficaram submetidas a uma intensa concorrência internacional, de outro, a internacionalização dessas empresas aumentou significativamente o acesso a novos mercados e novas fontes de informação. Com isso, o conhecimento e a inovação passaram a ser vistos como importantes forças tanto de sobrevivência quanto de aquisição de vantagens competitivas na economia brasileira.

Porém, o processo de inovação tecnológica da indústria brasileira normalmente é percebido como voltado à chamada inovação de processo, ou seja, à adoção de novos métodos de produção a fim de aumentar a eficiência produtiva ou viabilizar a fabricação de novos produtos. Realmente, de acordo com a Pesquisa Industrial da Inovação Tecnológica (Pintec) de 2003, realizada pelo Instituto Brasileiro de Geografia e Estatística (IBGE), 24\% das empresas industriais brasileiras inovaram em processo, sendo esse número de $18 \%$ para a inovação de produto - com uma interseção de $12 \%$ entre ambos os tipos de inovação.

Esses novos métodos produtivos se originariam na tentativa de equiparação a determinados competidores e se tornariam viáveis a partir da difusão de inovações realizadas em outras firmas, notoriamente aquelas do setor de bens de capital. ${ }^{1}$ Em outras palavras, o esforço inovativo das empresas industriais brasileiras estaria mais voltado à absorção do conhecimento gerado externamente, via aquisições de máquinas e equipamentos (M\&E) para a inovação, do que propriamente à geração de conhecimento internamente à firma, via investimentos em pesquisa e desenvolvimento (P\&D). Corroborando essa ideia, ainda segundo a Pintec de 2003, enquanto 5,24\% das empresas industriais brasileiras realizaram investimentos em $\mathrm{P} \& \mathrm{D}$ - com uma intensidade média de $0,53 \%$ em relação ao faturamento - , esse número é de $17,24 \%$ no caso de M\&E - com uma intensidade média de 1,22\%. De acordo com a mesma pesquisa, $80,3 \%$ das empresas avaliam seus investimentos em aquisições de M\&E como sendo de alta ou média importância para suas atividades inovativas. Com relação aos dispêndios em P\&D, apenas $20,7 \%$ lhes atribuem a mesma importância. 
Com isso em mente, este trabalho tem o objetivo de identificar algumas das características do processo de inovação tecnológica na indústria brasileira, particularmente no que diz respeito às alternativas — não necessariamente excludentes — entre dispêndios em P\&D e aquisições de M\&E. Dentro dessa perspectiva, procurar-se-á caracterizar os determinantes: (i) da decisão de se investir em cada uma dessas alternativas; (ii) do nível desses investimentos; (iii) do impacto destes na geração de estoque de conhecimento das firmas (que se manifesta na produção por meio das inovações); e (iv) da contribuição desse estoque para suas respectivas produtividades. Para tal, a estratégia empírica proposta neste trabalho se baseará no chamado modelo CDM - a partir de Crépon, Duguet e Mairesse (1998) —, cujas equações estruturais, conforme explicitadas mais adiante, compreendem justamente esses objetivos.

Com tal intuito, este trabalho compreende quatro outras seções além desta introdução. Na primeira delas, serão abordadas as relações entre os processos produtivo e inovativo da firma que constituirão o modelo CDM. Já a segunda seção detalhará tanto a especificação empírica quanto os devidos métodos de estimação. Finalmente, as duas últimas seções apresentarão, respectivamente, os resultados obtidos e as considerações finais.

\section{CONHECIMENTO E PRODUTIVIDADE}

A partir da publicação da primeira edição do Manual de Oslo, em 1992, foi desenvolvida, em diversos países, uma gama de pesquisas de inovação, permitindo o desenvolvimento de uma literatura até então ainda pouco explorada. $^{2}$ Uma questão que tem recebido parte significativa do foco das atenções é a relação entre produtividade e estoque de conhecimento da firma. A abordagem imediata é trabalhar, então, com o conhecimento como um insumo específico na função de produção, tal como, assumindo uma função Cobb-Douglas:

$$
Q_{i t}=A X_{i t}^{\alpha} K_{i t}^{\beta} e^{\varepsilon_{i t}}
$$

onde, $Q, A, X, K$ e $\varepsilon$ representam, respectivamente, a taxa de produtividade; uma constante de eficiência; um vetor contendo variáveis tais como traba- 
lho, capital físico, capital humano etc.; o estoque de conhecimento; e o termo de erro.

De início, esse estoque de conhecimento seria identificado com o estoque de $\mathrm{P} \& \mathrm{D},{ }^{3}$ abordagem essa que sofre de sérios problemas de robustez (Mairesse e Sassenou, 1991). Primeiramente, os efeitos dos investimentos em P\&D na produção são bastante incertos e ocorrem somente após certa defasagem temporal. Além disso, efeitos de outros fatores de produção podem ocorrer simultaneamente aos de P\&D, tornando estes de difícil identificação.

A superação desse problema veio com o reconhecimento de que os investimentos em P\&D são, de fato, um insumo (ou input) do processo de inovação, e o que afeta realmente a produção das firmas é o produto (ou output) desse processo. A partir dessa perspectiva, então, o termo relativo ao estoque de conhecimento na equação (1) passa a ser representado pela manifestação desse estoque na produção, ou seja, a própria inovação em si (mais precisamente, alguma medida de output do processo de inovação).

O passo seguinte, então, passa a ser a identificação dos determinantes da geração desse estoque de conhecimento, ou, em outras palavras, a construção das relações que fazem os diversos inputs gerarem esse output. Esse processo de transformação dos esforços inovativos em inovação foi denominado por Griliches (1979) “função de produção do conhecimento". Assumindo uma especificação geral, pode-se escrevê-la como (Criscuolo, Haskel e Slaughter, 2005):

$$
\Delta K_{i}=f\left(H_{i}, K_{i i}, K_{i_{-} i}\right)
$$

onde $\Delta K_{i}$ representa o estoque de conhecimento gerado pela firma $i$ em determinado período; $H_{i}$, o esforço no processo de criação de conhecimento; e $H_{i i}$ e $H_{i_{-}}$, os fluxos de ideias oriundas, respectivamente, interna e externamente à firma. Finalmente, esse esforço inovativo — os inputs — pode ser determinado: pelo tamanho e idade da firma, pela existência de oportunidades tecnológicas (technology push) ou de demanda (demand pull), pelo ambiente organizacional e tecnológico da firma, pelo ambiente de concorrência do mercado e pela existência de financiamento (interno ou externo à firma) a esses esforços (Klomp e van Leeuwen, 2002). 
Dessa forma, a questão apontada anteriormente a respeito da relação entre produtividade e estoque de conhecimento da firma envolve três fases possivelmente identificáveis: a decisão referente ao nível de esforço inovativo empregado pela firma, a relação entre esse esforço e o produto inovativo gerado, e, finalmente, o impacto dessa inovação na produção da firma. Essa abordagem evita, então, a questão da defasagem temporal com que os investimentos em P\&D impactam a produção, já que reconhece que o que gera esse impacto é a inovação em si, e não propriamente os esforços envolvidos em torno dela.

Porém, a estimação de cada uma dessas fases envolve uma série de questões econométricas, tanto em virtude de produtividade, inovação e investimentos em atividades inovativas serem variáveis endogenamente determinadas, quanto pela truncagem existente nos investimentos em inovação - questão que será abordada adiante. Assim, a estimação dessas fases recai em vieses tanto de seleção quanto de simultaneidade, tornando necessária a consideração desses aspectos para a adequada estimação de cada uma delas.

Com o intuito de resolver essas questões, Crépon, Duguet e Mairesse (1998) desenvolveram um modelo estrutural assumindo que as firmas, inicialmente, decidem o grau de seus esforços inovativos, esforços esses que produzirão uma determinada quantidade de conhecimento que será então utilizado na produção. No modelo CDM, o esforço inovativo é descrito pela seguinte equação:

$$
i_{i}^{*}=z_{i}^{\prime} \beta+e_{i}
$$

onde $i_{i}^{\star}$ representa uma variável latente referente aos investimentos em inovação e $z_{i}$, um vetor de determinantes desses investimentos. No entanto, todas as firmas realizam, de alguma forma, um determinado esforço inovativo, mas o contabilizam como tal apenas a partir de um determinado nível. ${ }^{4}$ Assim, assume-se a seguinte equação de seleção a respeito de a firma reportar esses investimentos:

$$
i d_{i}=\left\{\begin{array}{lll}
1 & \text { se } & i d_{i}^{*}=w_{i}^{\prime} \alpha+\varepsilon_{i}>c \\
0 & \text { se } & i d_{i}^{*}=w_{i}^{\prime} \alpha+\varepsilon_{i} \leq c
\end{array}\right.
$$


onde $i d_{i}$ é uma variável binária endógena que leva os valores um ou zero para as empresas que, respectivamente, reportaram ou não os investimentos em atividades inovativas. Por sua vez, $i d_{i}^{*}$ é a variável latente que faz com que as firmas reportem os seus investimentos quando eles superam o corte $c$, sendo $w_{i}$ um vetor de variáveis que influenciam a decisão do grau de investimento das firmas. Dessa forma, condicionado à contabilização das atividades inovativas, observa-se o nível de recursos investidos de tal forma que:

$$
i_{i}=\left\{\begin{array}{lll}
i_{i}^{\star}=z_{i}^{\prime} \beta+e_{i} & \text { se } & i d_{i}=1 \\
0 & \text { se } & i d_{i}=0
\end{array}\right.
$$

onde $i_{i}$ representa o esforço inovativo observado.

A equação seguinte descreve, conforme denominada anteriormente, a função de produção do conhecimento a partir da suposição de uma função Cobb-Douglas e da transformação logarítmica das variáveis:

$$
g_{i}=i_{i}^{\star} \gamma+x_{i}^{\prime} \delta+u_{i}
$$

onde $g_{i}$ e $x_{i}$ representam, significativamente, o conhecimento gerado e um vetor de outros determinantes (além dos investimentos em atividades inovativas) na produção desse conhecimento. Finalmente, tem-se uma função de produtividade:

$$
y_{i}=\pi_{1} k_{i}+\pi_{2} g_{i}+\pi_{3} l_{i}+\pi_{4} h_{i}+v_{i}
$$

onde $y_{i}$ representa a produtividade do trabalho; $k_{i}$, a intensidade de capital; $l_{i}$, o número de funcionários; e $h_{i}$, outras variáveis determinantes da produtividade (todas em logaritmo). As equações (4), (5), (6) e (7) compõem, então, o Modelo CDM. Desde o trabalho de Crépon et al. (1998), várias especificações diferentes dessas equações foram desenvolvidas e vários métodos de estimação utilizados. ${ }^{5}$ Na próxima seção, serão expostos os procedimentos seguidos neste trabalho.

\section{ESTRATÉGIA EMPÍRICA}

Para a devida implementação do modelo apresentado na seção anterior foram utilizadas a Pintec e a Pesquisa Industrial Anual (PIA) de 2000, ambas 
realizadas pelo IBGE, além das bases de dados da Secretaria de Comércio Exterior (Secex), do Ministério do Desenvolvimento, Indústria e Comércio Exterior (MDIC), referentes a 1998 e 2000.

A partir dessas fontes, as variáveis utilizadas ao longo do trabalho serão organizadas em determinados grupos. O primeiro deles é aquele referente ao ambiente organizacional da empresa, que será aqui chamado de $X_{1}$, abrangendo as seguintes variáveis: número de funcionários, além de duas variáveis binárias referentes ao fato de a firma pertencer, respectivamente, a um grupo nacional ou estrangeiro.

Em seguida, há outro grupo de variáveis referente ao ambiente concorrencial da empresa, $X_{2}$, com as variáveis: participação setorial a dois dígitos da Classificação Nacional de Atividade Econômica (CNAE) e duas variáveis binárias que levam valor unitário no caso, respectivamente, de a firma ter exportado ao longo do ano corrente de 1998 (exportação defasada) e de seu principal mercado se encontrar no exterior (refletindo o ambiente de competição em que a empresa está inserida). Ainda, tem-se um terceiro grupo $\left(X_{3}\right)$, referente à disponibilidade de financiamento à inovação, com duas variáveis binárias que levam o valor unitário caso a empresa tenha realizado esse financiamento por meio, respectivamente, de fontes públicas ou privadas (terceiros).

Já o quarto grupo $\left(X_{4}\right)$ corresponde às distintas fontes de informação para a inovação: fontes internas à empresa, outra empresa do grupo, fornecedores, clientes, concorrentes, universidade e governo. Esta última variável binária recebe valor unitário caso a firma reporte, no questionário da Pintec, ter recebido algum suporte do governo para suas atividades inovativas. Já as demais, quando ela apontar cada uma dessas fontes como sendo de alta importância para o processo de inovação.

Finalmente, há um quinto grupo $\left(X_{5}\right)$, correspondente às relações da empresa com as demais, abrangendo: uma variável cujo valor é a soma de investimentos em P\&D de todas as empresas do setor (a três dígitos da CNAE) subtraída do investimento da própria firma (representando o potencial de transbordamento de P\&D do setor); e uma variável binária referente ao envolvimento em arranjos cooperativos com vistas ao desenvolvimento de atividades inovativas. A tabela 1 procura sintetizar todas essas variáveis utilizadas ao longo deste trabalho. 
Tabela 1: Quadro-síntese das variáveis utilizadas

\begin{tabular}{|c|c|c|}
\hline Variáveis & Descrição & Fontes \\
\hline Produtividade & Valor agregado por empregado (em 2000). & PIA \\
\hline Intensidade de inovação & $\begin{array}{l}\text { Percentual da receita total de } 2000 \text { originado a partir } \\
\text { de produtos novos ou significativamente aprimorados, } \\
\text { sendo esses implementados entre } 1998 \text { e } 2000 \text {. Uma } \\
\text { vez que a Pintec fornece esse percentual relativo a } \\
\text { vendas internas e exportações, foram necessários os } \\
\text { valores das exportações e a dedução destas na receita } \\
\text { total para o cálculo das vendas internas. Ainda, } \\
\text { realizou-se uma transformação logística nessa variável. }\end{array}$ & $\begin{array}{c}\text { Pintec, PIA (receita) } \\
\text { e Secex } \\
\text { (exportações) }\end{array}$ \\
\hline Inovação & $\begin{array}{l}\text { Variável binária que recebe valor unitário caso a firma } \\
\text { tenha realizado inovação de produto ou de processo } \\
\text { entre } 1998 \text { e } 2000 \text {. }\end{array}$ & Pintec \\
\hline Inovação de produto & $\begin{array}{l}\text { Variável binária que recebe valor unitário caso a } \\
\text { firma tenha introduzido produto tecnologicamente } \\
\text { novo ou significativamente aprimorado, entre } 1998 \\
\text { e } 2000 \text {. }\end{array}$ & Pintec \\
\hline Inovação de processo & $\begin{array}{l}\text { Variável binária que recebe valor unitário caso a } \\
\text { firma tenha introduzido processo tecnologicamente } \\
\text { novo ou significativamente aprimorado, entre } 1998 \\
\text { e } 2000 \text {. }\end{array}$ & Pintec \\
\hline P\&D por empregado & Investimentos em P\&D por empregado (em 2000). & Pintec (P\&D) e PIA \\
\hline Investimento em P\&D & $\begin{array}{l}\text { Variável binária que recebe valor unitário caso a } \\
\text { firma tenha realizado investimentos em P\&D } \\
\text { no ano } 2000 .\end{array}$ & Pintec \\
\hline M\&E por empregado & $\begin{array}{l}\text { Aquisições de máquinas e equipamentos (M\&E) por } \\
\text { empregado (em 2000). }\end{array}$ & Pintec (M\&E) e PIA \\
\hline Investimento em M\&E & $\begin{array}{l}\text { Variável binária que recebe valor unitário caso a } \\
\text { firma tenha realizado investimentos em M\&E no } \\
\text { ano } 2000 .\end{array}$ & Pintec \\
\hline Número de funcionários & $\begin{array}{l}\text { Número médio de funcionários ao longo do } \\
\text { ano } 2000 .\end{array}$ & PIA \\
\hline Grupo nacional & $\begin{array}{l}\text { Variável binária que recebe valor unitário caso a firma } \\
\text { faça parte de um grupo de empresas cujo capital } \\
\text { controlador seja nacional. }\end{array}$ & Pintec \\
\hline Grupo estrangeiro & $\begin{array}{l}\text { Variável binária que recebe valor unitário caso a } \\
\text { firma faça parte de um grupo de empresas cujo } \\
\text { capital controlador seja estrangeiro ou nacional e } \\
\text { estrangeiro. }\end{array}$ & Pintec \\
\hline Participação setorial & $\begin{array}{l}\text { Percentual da receita da empresa no total do setor, } \\
\text { a dois dígitos da CNAE (em 2000). }\end{array}$ & PIA \\
\hline Exportação defasada & $\begin{array}{l}\text { Variável binária que recebe valor unitário caso a firma } \\
\text { tenha realizado exportações no ano } 1998 .\end{array}$ & Secex \\
\hline Competição & $\begin{array}{l}\text { Variável binária que recebe valor unitário caso o } \\
\text { principal mercado da firma, entre } 1998 \text { e } 2000, \\
\text { se situe no exterior. }\end{array}$ & Pintec \\
\hline Financiamento público & $\begin{array}{l}\text { Variável binária que recebe valor unitário caso a firma } \\
\text { tenha utilizado fontes públicas de financiamento das } \\
\text { atividades inovativas (em 2000). }\end{array}$ & Pintec \\
\hline
\end{tabular}




\section{(Continuação da tabela 1)}

\begin{tabular}{|c|c|c|}
\hline Variáveis & Descrição & Fontes \\
\hline Financiamento privado & $\begin{array}{l}\text { Variável binária que recebe valor unitário caso a } \\
\text { firma tenha utilizado fontes privadas (de terceiros) de } \\
\text { financiamento das atividades inovativas (em 2000). }\end{array}$ & Pintec \\
\hline Fonte: interna & $\begin{array}{l}\text { Variável binária que recebe valor unitário caso a firma } \\
\text { aponte fontes internas à empresa como sendo de } \\
\text { alta importância para o processo de inovação (entre } \\
1998 \text { e 2000). }\end{array}$ & Pintec \\
\hline Fonte: grupo & $\begin{array}{l}\text { Variável binária que recebe valor unitário caso a firma } \\
\text { aponte outra empresa do grupo como sendo de alta } \\
\text { importância para o processo de inovação (entre } 1998 \\
\text { e 2000). }\end{array}$ & Pintec \\
\hline Fonte: fornecedor & $\begin{array}{l}\text { Variável binária que recebe valor unitário caso a firma } \\
\text { aponte fornecedores de máquinas, equipamentos, } \\
\text { materiais, componentes ou softwares como sendo de } \\
\text { alta importância para o processo de inovação (entre } \\
1998 \text { e 2000). }\end{array}$ & Pintec \\
\hline Fonte: clientes & $\begin{array}{l}\text { Variável binária que recebe valor unitário caso a firma } \\
\text { aponte clientes ou consumidores como sendo de alta } \\
\text { importância para o processo de inovação (entre } 1998 \\
\text { e 2000). }\end{array}$ & Pintec \\
\hline Fonte: concorrentes & $\begin{array}{l}\text { Variável binária que recebe valor unitário caso a firma } \\
\text { aponte concorrentes como sendo de alta importância } \\
\text { para o processo de inovação (entre } 1998 \text { e 2000). }\end{array}$ & Pintec \\
\hline Fonte: universidades & $\begin{array}{l}\text { Variável binária que recebe valor unitário caso a } \\
\text { firma aponte universidades e institutos de pesquisa } \\
\text { como sendo de alta importância para o processo de } \\
\text { inovação (entre } 1998 \text { e 2000). }\end{array}$ & Pintec \\
\hline Fonte: governo & $\begin{array}{l}\text { Variável binária que recebe valor unitário caso a firma } \\
\text { aponte ter recebido algum suporte do governo para } \\
\text { suas atividades inovativas (entre } 1998 \text { e 2000). }\end{array}$ & Pintec \\
\hline Transbordamento & $\begin{array}{l}\text { Soma dos investimentos em P\&D de todas as empresas } \\
\text { do setor (a três dígitos da CNAE) subtraída do } \\
\text { investimento realizado pela própria firma (em 2000). }\end{array}$ & Pintec \\
\hline Cooperação & $\begin{array}{l}\text { Variável binária que recebe valor unitário caso a } \\
\text { firma, entre } 1998 \text { e } 2000 \text {, tenha estado envolvida } \\
\text { em arranjos cooperativos com outra organização } \\
\text { com vistas a desenvolver atividades inovativas. }\end{array}$ & Pintec \\
\hline Intensidade de capital & $\begin{array}{l}\text { Estoque de capital por empregado. Estoque de } \\
\text { capital construído a partir da metodologia descrita } \\
\text { em Alves e Silva (2007). }\end{array}$ & PIA \\
\hline
\end{tabular}


Assim, utilizando a nomenclatura da seção anterior, as variáveis independentes do sistema são definidas da seguinte forma: ${ }^{6}$

$$
\begin{aligned}
& w_{i}=\left\{X_{1}, X_{2}, X_{3}\right\} \\
& z_{i}=\left\{X_{1}, X_{2}, X_{3}, X_{4}, X_{5}\right\} \\
& x_{i}=\left\{X_{4}, l_{i}\right\} \\
& h_{i}=\left\{X_{1}\right\}
\end{aligned}
$$

Os inputs do processo de inovação serão caracterizados pelos investimentos em $\mathrm{P} \& \mathrm{D}$, de um lado, e pelas aquisições de máquinas e equipamentos para a inovação, de outro. Já os seus outputs serão representados, em um primeiro modelo, por duas variáveis binárias referentes às inovações em produto e em processo, e, em um segundo, pela participação percentual da receita da firma oriunda de produto tecnologicamente novo ou significativamente aprimorado ${ }^{7}$ - normalmente denominado intensidade de inovação.

A partir dessas variáveis, então, serão estimadas as equações (4), (5), (6) e (7). As duas primeiras serão estimadas por meio do chamado modelo de seleção de Heckman (Heckman, 1979), por máxima verossimilhança. Esse procedimento permite a adequada estimação da equação (5) ao levar em consideração a existência de uma truncagem nas variáveis referentes a investimentos em inovação, proveniente da ideia sintetizada na equação (4) de que nem todas as firmas reportam seus esforços inovativos, mas o fazem apenas a partir do momento em que esses esforços superem um determinado nível. Caso esse problema de seleção fosse um fenômeno aleatório, a equação (5) poderia ser estimada normalmente por mínimos quadrados ordinários. Porém, supondo-se que os níveis de investimentos em inovação não são aleatórios, mas, sim, determinados por alguns fatores referentes a cada uma das firmas, essa possibilidade de a firma estar ou não inclusa na seleção é de fato uma variável omitida na equação (5). O modelo de Heckman procura, então, contornar esse viés de seleção, levando em consideração as probabilidades de cada firma estar inclusa na amostra, determinadas pela equação (4).

Quanto à equação (6), é bastante provável que variáveis não observáveis que afetem o output do processo de inovação - portanto, inclusas no erro — também influenciem o nível de investimentos em atividades inovativas, constituindo um problema de endogeneidade. Assim, a estimação dessa 
equação é realizada utilizando-se o valor previsto desse esforço a partir do sistema anterior, instrumentalizando a variável referente aos inputs. Para essa estimação, são utilizados dois probits ou um tobit, de acordo com os outputs de inovação utilizados (respectivamente, as variáveis binárias de inovação de produto e processo ${ }^{8}$ e a intensidade de inovação)..$^{9}$ Os probits naturalmente são aplicados nos casos de variáveis dependentes binárias, como as duas de inovação, enquanto o tobit, por sua vez, é utilizado em virtude de a intensidade de inovação ser uma variável contínua que não assume valores negativos.

Finalmente, a equação (7) será estimada via mínimos quadrados ordinários, também instrumentalizando os outputs do processo inovativo por meio de seus valores previstos na estimação anterior.

\section{RESULTADOS}

A amostra utilizada neste trabalho consiste nas empresas presentes na Pintec de 2000, porém excluídas aquelas que: (i) apresentam valor agregado, pessoal ocupado ou estoque de capital iguais a zero; (ii) se situam abaixo ou acima, respectivamente, dos percentis 1 e 99 no que se refere à produtividade do trabalho, à intensidade do capital e aos investimentos em P\&D e em M\&E por empregado (os percentis destas duas últimas variáveis foram calculados apenas para valores maiores que zero). A condição que se refere à necessidade de a empresa apresentar informações acerca de seu estoque de capital implica a exclusão daquelas que não pertençam ao estrato certo da PIA (ou seja, das firmas com menos de 30 funcionários). Isso porque apenas as empresas desse estrato estão inclusas na metodologia empregada em Alves e Silva (2007) para a construção dessa variável.

Após essas exclusões, a amostra consistiu em um total de 31.059 empresas. A tabela 2 apresenta algumas estatísticas descritivas a respeito da amostra empregada neste trabalho. Como normalmente ocorre nas variáveis econômicas, percebe-se uma acentuada assimetria na distribuição dos valores, inclusive com determinadas variáveis apresentando médias superiores ao terceiro quartil. Porém, o mais importante é notar que a média dos investimentos em $M \& E$ se mostra quase quatro vezes superior àqueles em $P \& D$. De fato, essa diferença se mostra inferior a três vezes nos quartis, sugerindo a existência de uma maior discrepância acima do quartil superior. 
Tabela 2: Estatísticas descritivas, variáveis contínuas

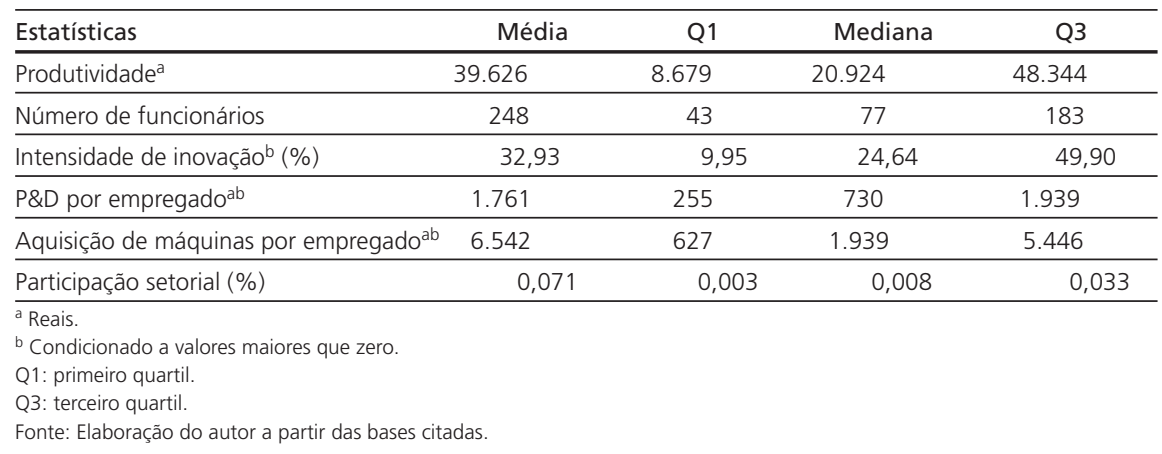

Tabela 3: Estatísticas descritivas, variáveis binárias

\begin{tabular}{lc}
\hline Variáveis Binárias & $\%^{\mathrm{a}}$ \\
\hline Investidoras em P\&D & 14,92 \\
\hline Investidoras em M\&E & 35,16 \\
\hline Inovadoras & 50,08 \\
\hline Inovadoras de produto & 33,36 \\
\hline Inovadoras de processo & 40,35 \\
\hline Fonte: interna & 25,58 \\
\hline Fonte: grupo & 12,19 \\
\hline Fonte: fornecedor & 20,64 \\
\hline Fonte: clientes & 20,81 \\
\hline Fonte: concorrentes & 10,03 \\
\hline Fonte: universidades & 3,61 \\
\hline Fonte: governo & 9,30 \\
\hline Competição & 5,96 \\
\hline Cooperação & 10,83 \\
\hline Exportação defasada & 37,74 \\
\hline
\end{tabular}

a Percentual de valores iguais a um.

Fonte: Elaboração do autor a partir das bases citadas.

Por sua vez, a tabela 3 expõe algumas das variáveis binárias utilizadas ao longo deste trabalho. Por meio dela, nota-se um percentual muito maior de empresas da amostra que realizaram investimentos em M\&E em comparação aos em P\&D (35\% contra quase 15\%). Quanto às empresas inovadoras, percebe-se um maior número das que inovaram em processo, apesar de haver uma clara interseção entre os dois tipos de inovação. Das diversas fontes de informações para a inovação, enquanto há uma importância muito grande dos fornecedores e dos clientes, as universidades se mostram exercendo um 
papel pouco relevante. Finalmente, ainda é interessante apontar o fato de que, apesar de apenas quase $6 \%$ das empresas da amostra terem seu foco no mercado externo (variável competição), mais de 37\% delas realizaram exportações no ano 1998. Em outras palavras, quase um terço delas se volta principalmente ao mercado interno, mas estão inseridas internacionalmente.

Voltando-se à estimação do modelo apresentado na seção anterior, a tabela 4 apresenta os resultados do modelo de seleção de Heckman por máxima verossimilhança, com relação tanto aos investimentos em P\&D quanto às aquisições de $M \& E$ - equações (4) e (5). Interessantes conclusões podem ser extraídas dessas estimações:

- Percebe-se em ambas as estimações que, quanto maior for o tamanho da empresa (medido pelo número de funcionários), maior será a probabilidade de esta decidir realizar o investimento. Porém, uma vez que a empresa tenha realizado esse investimento, sua intensidade decai de acordo com o tamanho. No que se refere a investimentos em P\&D, o primeiro resultado coincide com as evidências encontradas para a França - Crépon et al. (1998), Griffith et al. (2006) e Mairesse e Mohnen (2003) — , e para a Alemanha, a Espanha e o Reino Unido - Griffith et al. (2006) e Mairesse e Mohnen (2003). Porém, esses estudos não encontram uma relação significativa entre tamanho e intensidade desses investimentos. ${ }^{10}$ Por outro lado, uma relação negativa também é encontrada por Loof e Heshmati (2002) para a Suécia e por Klomp e van Leeuwen (2002) para a Holanda. Já quanto a aquisições de M\&E, o resultado deste trabalho coincide com o encontrado por Duguet e Lelarge (2006) para a França. ${ }^{11}$

- As firmas que têm o exterior como os seus principais mercados tendem a evitar mais a realização de investimentos em P\&D. Além disso, as que o fazem, investem menos que a média. Esses resultados diferem bastante do encontrado em Griffith et al. (2006) para França, Alemanha, Espanha e Reino Unido, em que a exposição à competição internacional parece aumentar a probabilidade de as firmas investirem em P\&D. Ainda, os autores encontraram uma relação positiva entre essa exposição e a intensidade de P\&D na França e na Espanha. Assim, essas evidências indicam que as empresas brasileiras e europeias que competem principalmente no exterior possuem estratégias diferentes. Enquanto estas se 
Tabela 4: Determinantes dos insumos da inovação

\begin{tabular}{|c|c|c|}
\hline & P\&D por empr. & M\&E por empr. \\
\hline \multicolumn{3}{|l|}{ Equação de investimento } \\
\hline Número de funcionários & $-0,692 * * *$ & $-0,784^{* * *}$ \\
\hline Competição & $-0,192 * *$ & $-0,160$ \\
\hline Cooperação & $0,225 * * *$ & $-0,012$ \\
\hline Transbordamento & $-6,631 * * *$ & $-1,324 * * *$ \\
\hline Participação setorial & $0,490 * * *$ & $0,408 * * *$ \\
\hline Financiamento público & $0,393 * * *$ & $0,296 * *$ \\
\hline Financiamento privado & 0,073 & 0,119 \\
\hline Grupo nacional & 0,046 & $0,291 * * *$ \\
\hline Grupo estrangeiro & $0,136^{*}$ & $0,552 * * *$ \\
\hline Exportação defasada & 0,044 & 0,018 \\
\hline Fonte: interna & $0,105^{\text {** }}$ & $-0,046$ \\
\hline Fonte: grupo & 0,079 & $0,280 * * *$ \\
\hline Fonte: fornecedor & $-0,107^{*}$ & $0,110 * *$ \\
\hline Fonte: clientes & $-0,054$ & $-0,031$ \\
\hline Fonte: concorrentes & $-0,096$ & $-0,040$ \\
\hline Fonte: universidades & 0,044 & 0,029 \\
\hline \multirow[t]{2}{*}{ Fonte: governo } & $-0,090$ & 0,061 \\
\hline & P\&D por empr. & M\&E por empr. \\
\hline \multicolumn{3}{|l|}{ Equação de decisão } \\
\hline Número de funcionários & $0,238 * * *$ & $0,168 * * *$ \\
\hline Competição & $-0,103^{*}$ & 0,029 \\
\hline Participação setorial & $0,155^{* * *}$ & $0,159 * * *$ \\
\hline Financiamento público & $0,571 * * *$ & $1,932 * * *$ \\
\hline Financiamento privado & $0,487 * * *$ & $2,146 * * *$ \\
\hline Grupo nacional & $0,118^{*}$ & $-0,054$ \\
\hline Grupo estrangeiro & 0,074 & 0,017 \\
\hline Exportação defasada & $0,193 * * *$ & $-0,051$ \\
\hline Número de observações & 12.545 & 12.538 \\
\hline Censuradas & 9.598 & 6.940 \\
\hline Não censuradas & 2.947 & 5.598 \\
\hline Wald & $4.399,2 * * *$ & $2.612,9 * * *$ \\
\hline
\end{tabular}

Constantes e controles setoriais não reportados.

Todas as váriáveis, com exceção das dummies, estão em logaritmo natural.

$* * *$ Significativo a $1 \%$.

** Significativo a $5 \%$.

* Significativo a $10 \%$.

Fonte: Elaboração do autor a partir das bases citadas. 
inserem internacionalmente via geração de conhecimento próprio, o mesmo não pode ser dito das firmas brasileiras.

- A cooperação com outras empresas com vistas ao desenvolvimento de inovações tem uma relação positiva com o nível de gastos em P\&D.

- Um maior potencial de transbordamento de P\&D leva a menores níveis de investimentos em ambas as alternativas. Tais resultados indicam uma certa substituibilidade entre P\&D próprio e de terceiros.

- Em ambas as estimações, percebem-se relações positivas tanto entre o marketshare e a decisão de investir, quanto entre aquele e o nível de investimento. Esses resultados também foram observados por Crépon et al. (1998) na França e Klomp e van Leeuwen (2002) na Holanda.

- Como seria de se esperar, a disponibilidade de financiamento tanto público quanto privado parece levar à decisão afirmativa de investimento, tanto em P\&D quanto em M\&E. Já para um maior nível destes, apenas o financiamento público parece ter uma relação positiva e significativa.

- O fato de a empresa ter exportado anteriormente parece ter uma correlação positiva e significativa apenas com a decisão de investimento em P\&D — coincidindo com o encontrado por Duguet e Lelarge (2006) na França.

- Das diversas fontes de informações para a inovação, a única que parece ter uma relação positiva com um maior nível de dispêndios em P\&D é a própria empresa. Já no caso de aquisições de M\&E, isso ocorre em duas delas: outras empresas do grupo e fornecedores. Esta última, aliás, apresenta uma relação negativa com investimentos em P\&D.

Com isso, as aquisições de $M \& E$ parecem estar condicionadas à disponibilidade de financiamento - especialmente público - e a inovações desenvolvidas por fornecedores ou outras empresas do grupo, ${ }^{12}$ pouco influindo as condições competitivas. Já os dispêndios em P\&D parecem mais relacionados a firmas voltadas principalmente ao mercado interno, mas inseridas no mercado internacional. De qualquer forma, a disponibilidade de financiamento também se mostra relevante para estes.

Por sua vez, a tabela 5 mostra os resultados da estimação da equação (6), por meio de dois probits e um tobit, nos casos, respectivamente, da utilização das variáveis de inovação de produto e de processo, e da intensidade de inovação. As conclusões que podem ser levantadas dessa estimação são: 
Tabela 5: Determinantes do produto do processo inovativo

\begin{tabular}{|c|c|c|c|}
\hline & Inovação de produto & Inovação de processo & Intensidade de inovação \\
\hline P\&D por empreg. & $0,742^{* * *}$ & $0,430 * * *$ & $0,085^{* * *}$ \\
\hline M\&E por empr. & $-0,453^{* * *}$ & $-0,161$ & 0,252 \\
\hline Número de funcionários & $0,115^{* * *}$ & $0,246^{* * *}$ & $4,871 * * *$ \\
\hline Intensidade de capital & - & $-0,056^{* *}$ & - \\
\hline Fonte: interna & $0,405^{* * *}$ & $0,817 * * *$ & $-1,113 * * *$ \\
\hline Fonte: grupo & $0,906 * * *$ & $0,563^{* * *}$ & $4,340 * * *$ \\
\hline Fonte: fornecedor & $0,276^{* * *}$ & $1,227 * * *$ & $0,712 * *$ \\
\hline Fonte: clientes & $0,871 * * *$ & $0,300 * * *$ & $4,004^{* * *}$ \\
\hline Fonte: concorrentes & $0,388^{* * *}$ & $0,474 * * *$ & $0,899 * *$ \\
\hline Fonte: universidades & $0,569 * * *$ & $-0,123$ & $2,800 * * *$ \\
\hline Fonte: governo & $0,412 * * *$ & $1,083^{* * *}$ & $1,1012^{* * *}$ \\
\hline Número de observações & 12.482 & 12.488 & 12.488 \\
\hline Pseudo $\mathrm{R}^{2}$ & 0,3386 & 0,3676 & 0,1147 \\
\hline \multicolumn{4}{|c|}{$\begin{array}{l}\text { Constantes e controles setoriais não reportados. } \\
\text { Todas as váriáveis explicativas, com exceção das dummies, estão em logaritmo natural. } \\
\text { ** Significativo a } 1 \% \text {. } \\
\text { ** Significativo a } 5 \% \text {. } \\
\text { * Significativo a } 10 \% \text {. } \\
\text { Fonte: Elaboração do autor a partir das bases citadas. }\end{array}$} \\
\hline
\end{tabular}

- Quanto maior for o nível relativo de investimentos em P\&D, maior será a probabilidade de as firmas inovarem tanto em produto quanto em processo, e maiores serão suas participações na receita oriundas de produtos novos.

- Há uma relação negativa entre aquisições de máquinas e equipamentos e inovações de produto. Esse resultado não coincide com o encontrado por Duguet e Lelarge (2006) para a França, que encontraram uma relação positiva entre esses investimentos e inovação de processo, porém não significativa para o caso de inovação de produto.

- Tanto a probabilidade de inovar quanto a intensidade de inovação tendem a aumentar com o tamanho da empresa. Evidências semelhantes foram encontradas para os casos: da inovação de processo, para a França - Griffith et al. (2006), Mairesse e Mohnen (2003) e Duguet e Lelarge (2006) —, para a Alemanha, a Inglaterra e a Espanha - Griffith et al. (2006) e Mairesse e Mohnen (2003) —; da intensidade de inovação, para a França, a Alemanha, a Inglaterra e a Espanha - Mairesse e Mohnen (2003) —, e para a Suécia — Loof e Heshmati (2002). Por outro lado, essa relação não se mostrou significativa para: a inovação 
de produto, para a França - Griffith et al. (2006) e Duguet e Lelarge (2006) - , e para a Alemanha, a Inglaterra e a Espanha — Griffith et al. (2006) —; a intensidade de inovação, para a França, por Crépon et al. (1998).

- Todas as fontes de informações se mostram relevantes para o processo inovativo, com duas exceções: a universidade para a inovação de processo e a própria empresa para a intensidade de inovação.

Assim, apesar da complementaridade existente entre os investimentos em P\&D e em M\&E, percebe-se que, descontada a ação daquele, este tem uma influência negativa na produtividade do processo inovativo das firmas. Essa evidência colabora com a visão acerca da existência de uma dependência tecnológica das firmas — em relação a seus fornecedores — que confiam nessa modalidade de esforço inovativo. De um lado, essas firmas buscam a inovação prioritariamente como um meio de redução de custos, em detrimento da exploração de alguma vantagem tecnológica em termos de produto ou marca, e, de outro, elas se apoiam em fontes externas à firma para a realização da inovação. De fato, essa caracterização vai de encontro à chamada categoria de firmas supplier-dominated, conforme a taxonomia de $\mathrm{Pa}$ vitt (1984).

Finalmente, por meio da tabela 6 nota-se a devida influência dos fatores na produtividade das empresas. Em primeiro lugar, percebe-se que as firmas que inovam em produto possuem, em média, uma produtividade $85 \%{ }^{13}$ superior às demais, resultado semelhante ao observado por meio da intensidade de inovação. Por outro lado, surpreendentemente, a inovação de processo não parece ter um efeito significativo sobre a produtividade das firmas. Igualmente interessante é a grande queda observada, de uma estimação para outra, no coeficiente referente ao número de funcionários. Esse fato mostra que a intensidade de inovação tem uma relação mais significativa com o tamanho da empresa do que propriamente as dummies de inovação.

Esses resultados coincidem com os encontrados para a França - por Mairesse e Mohnen (2003) e Crépon et al. (1998) — , para a Espanha e a Inglaterra - por Griffith et al. (2006) — e para a Suécia — por Loof e Heshmati (2002). Por outro lado, para Griffith et al. (2006) ambas as inovações se mostraram significativas e positivas para a França, e não significativas para a Alemanha. 
Tabela 6: Determinantes da produtividade

\begin{tabular}{lcc}
\hline & \multicolumn{2}{c}{ Produtividade } \\
\hline Inovação de produto & $0,618^{*}$ & - \\
\hline Inovação de processo & 0,019 & - \\
\hline Intensidade de inovação & - & $0,040^{*}$ \\
\hline Número de funcionários & $0,215^{*}$ & $0,060^{* * *}$ \\
\hline Intensidade de capital & $0,484^{*}$ & $0,501^{*}$ \\
\hline Grupo nacional & $0,135^{* *}$ & $0,121^{* *}$ \\
\hline Grupo estrangeiro & $0,288^{*}$ & $0,267^{*}$ \\
\hline Número de observações & 12.482 & 12.488 \\
\hline $\mathrm{R}^{2}$ ajustado & 0,3672 & 0,3645 \\
\hline Teste F & $95^{* * *}$ & $90^{* * *}$
\end{tabular}

Constantes e controles setoriais não reportados.

Todas as variáveis explicativas, com exceção das dummies, estão em logaritmo natural.

*** Significativo a $1 \% * *$. Significativo a $5 \%$. * Significativo a $10 \%$.

Fonte: Elaboração do autor a partir das bases citadas.

\section{CONCLUSÕES}

Ao longo deste trabalho, procurou-se identificar determinadas características do processo de inovação tecnológica da indústria brasileira, particularmente no que diz respeito às alternativas referentes tanto à absorção do conhecimento gerado externamente - por meio de aquisições de M\&E quanto à geração de conhecimento internamente à firma — via dispêndios em P\&D. Nesse sentido, identificaram-se os determinantes da decisão de se investir em cada uma dessas alternativas, do nível desses investimentos, além do impacto destes na inovação e desta no desempenho da firma.

A partir das estimações apresentadas, notou-se o condicionamento das aquisições de M\&E à disponibilidade de financiamento e a inovações desenvolvidas por fornecedores ou outras empresas do grupo, além de uma limitada influência das condições competitivas. Por sua vez, os investimentos em $\mathrm{P} \& \mathrm{D}$ estão mais vinculados a empresas voltadas principalmente ao mercado interno, porém inseridas internacionalmente.

Ainda, verificou-se uma maior produtividade marginal por parte dos dispêndios em $\mathrm{P} \& \mathrm{D}$ - em relação a aquisições de $\mathrm{M} \& \mathrm{E}$ - no processo de inovação da indústria brasileira. De fato, os resultados apresentados corroboram a visão acerca da existência de dependência tecnológica de uma parcela das empresas industriais brasileiras com relação a seus fornecedores ou outras empresas do grupo. Finalmente, constatou-se que as firmas que ino- 
vam em produto apresentam, em média, uma produtividade $85 \%$ superior às demais, significância essa não compartilhada pela inovação de processo.

Esses resultados sinalizam um potencial para uma aplicação mais eficiente de recursos nos esforços inovativos. De fato, apesar do enorme impacto da inovação de produto na produtividade das firmas, uma maior parcela daqueles recursos é dedicada a investimentos em M\&E, em detrimento aos em P\&D. Observando as influências desses dispêndios na inovação de produto (negativo no caso de M\&E, positivo no de $\mathrm{P} \& \mathrm{D}$ ), percebe-se, portanto, certa deficiência na aplicação daqueles recursos. Naturalmente, as aquisições de M\&E exercem uma influência positiva sobre a produtividade das firmas por meio de uma maior intensidade de capital. Porém, esta se torna maior explorando-se a complementaridade existente entre os investimentos em P\&D e as aquisições de M\&E.

\section{NOTAS}

1. Para uma discussão mais ampla neste sentido, vide Prochnik e Araújo (2005).

2. O Manual de Oslo foi desenvolvido no intuito de orientar e padronizar a metodologia de obtenção de dados e estatísticas em inovação e P\&D, sendo sucedido, então, por uma série de pesquisas, com destaque à Community Innovation Survey (CIS), envolvendo a Comunidade Europeia. Esse conjunto de iniciativas proporcionou aos estudiosos uma série de informações que possibilitaram uma investigação mais consistente em torno tanto do processo de inovação tecnológica, quanto dos esforços envolvidos nesse processo.

3. Vide Griliches (1979).

4. Por exemplo, determinados trabalhadores de certa empresa podem de fato dedicar parte de seu tempo no aprimoramento de técnicas produtivas, mas esses esforços podem acabar não sendo contabilizados como $\mathrm{P} \& \mathrm{D}$.

5. Para uma ampla revisão da literatura envolvendo o modelo CDM, vide Hall e Mairesse (2006).

6. Além dessas, variáveis binárias de setores a três dígitos da CNAE foram inseridas em todas as equações.

7. Tendo em vista a importância da inovação em processo para o desenvolvimento e para a viabilidade de fabricação de novos produtos, esse percentual, normalmente, também reflete esse tipo de inovação.

8. Na equação referente à inovação de processo, será incluída também como variável de controle a intensidade de capital da firma, seguindo, nesse ponto, a especificação de Griffith et al. (2006).

9. Essa variável também sofreu uma transformação logística. 
10. Com exceção de Griffith et al. (2006), que não utilizam nenhuma variável controlando pelo tamanho na segunda estimação.

11. Porém, esses autores utilizam a variável receita bruta como proxy para tamanho da empresa.

12. Descrição essa que vai de encontro ao que Pavitt (1984) apontou como firmas dominadas por fornecedores.

13. Tem-se: $\exp \left(0,618^{\star} 1\right)-1=0,8552$.

\section{REFERÊNCIAS BIBLIOGRÁFICAS}

ALVES, P.; SILVA, A. Estimativa do estoque de capital das empresas industriais brasileiras. Rio de Janeiro: Ipea, 2007 (a ser publicado). (Texto para Discussão.)

CRÉPON, B.; DUGUET, E.; MAIRESSE, J. Research, innovation and productivity: an econometric analysis at firm level. NBER Working Paper, n. 6696, 1998.

CRISCUOLO, C.; HASKEL, J.; SLAUGHTER, M. Global Engagement and the Innovation Activities of Firms. NBER Working Paper, n. 11479, 2005.

DUGUET, E.; LELARGE, C. Does patenting increase the private incentives to innovate? A microeconometric analysis. INSEE-CREST Working Paper, n. 2006-09, 2006.

GRIFFITH, R.; HUERGO, E.; MAIRESSE, J.; PETERS, B. Innovation and productivity across four european countries. NBER Working Paper, n. 12722, 2006.

GRILICHES, Z. Issues in Assessing the Contribution of R\&D to Productivity Growth. Bell Journal of Economics, v. 10, n. 1, p. 92-116, 1979.

HALL, B. H.; MAIRESSE, J. Empirical studies of innovation in the knowledge driven economy: introduction. Economics of Innovation and New Technology, v. 15, n. 4-5, p. 289-299, 2006.

HECKMAN, J. Sample selection bias as a specification error. Econometrica, v. 47, n. 1, p. 153$161,1979$.

KLOMP, L.; VAN LEEUWEN, G. On the contribution of innovation to multi-factor productivity growth. Cerem Research Paper, n. 201, 2002.

LOOF, H.; HESHMATI, A. Knowledge capital and performance heterogeneity: a firm-level innovation study. International Journal of Production Economics, v. 76, n.1, p. 61-85, 2002.

MAIRESSE, J.; MOHNEN. R\&D and productivity: a reexamination in light of the innovation surveys. Druid Summer Conference 2003 on Creating, Shearing and Transferring Knowledge. The role of Geography, Institutions and Organizations, 2003.

MAIRESSE, J.; SASSENOU, M. R\&D and productivity: a survey of econometric studies at the firm level. NBER Working Paper, n. 3666, 1991.

PAVITT, K. Sectoral patterns of technical change: towards a taxonomy and a theory. Research Policy, v. 13, n. 6, p. 343-373, 1984.

PROCHNIK, V.; ARAÚJO, R. Uma análise do baixo grau de inovação na indústria brasileira a partir do estudo das firmas menos inovadoras. In: DE NEGRI, J. A.; SALERNO, M. S. (Orgs.). Inovações, padrões tecnológicos e desempenho das firmas industriais brasileiras, Brasília: Ipea, 2005. 
